\title{
Digestibilidade Aparente de Dietas com Diferentes Níveis de Farelo de Canola para Cavalos 1
}

\author{
Kátia de Oliveira ${ }^{2}$, Carlos Eduardo Furtado ${ }^{3}$
}

\begin{abstract}
RESUMO - Foram utilizados quatro eqüinos, machos, com média de 3,5 anos e peso vivo entre 400-450 kg, distribuídos em um delineamento experimental em quadrado latino 4 x 4 (período x animal). Os níveis de inclusão do farelo de canola nas rações foram de 0,0 ; 2,5; 4,5 e 7,0\%, substituindo, respectivamente, 0; 35; 65 e 100\% da proteína bruta (PB) do farelo de soja. As rações foram isoprotéicas $(13 \%$ PB) e isocalóricas $(4250 \mathrm{kcal} / \mathrm{kg})$. Utilizou-se o método de coleta total de fezes para determinação dos coeficientes de digestibilidade dos nutrientes. Não houve efeito entre os níveis de substituição da proteína bruta do farelo de soja pelo farelo de canola para nenhum dos nutrientes avaliados. Os valores médios obtidos para os coeficientes de digestibilidade aparente da matéria seca, energia bruta, proteína bruta, fibra em detergente neutro e fibra em detergente ácido foram, respectivamente, 64,04; 55,82; 62,89; 51,20 e 42,05\%. Os concentrados para eqüinos podem ser formulados com substituição total da proteína bruta do farelo de soja pelo farelo de canola (nível de inclusão de 7\%), sem afetar adversamente a digestibilidade dos nutrientes, tornando-se, assim, uma fonte protéica alternativa para as dietas desta espécie.
\end{abstract}

Palavras-chave: coeficiente de digestibilidade, eqüinos, farelo de canola

\section{Apparent Digestibility of Diets with Different Levels of Canola Meal to Equines}

\begin{abstract}
Four male equines averaging 3.5 years old and live weight of $400-450 \mathrm{~kg}$ were distributed in a $4 \mathrm{x} 4$ Latin square (period $\mathrm{x}$ animal) experimental design. The inclusion of canola meal levels in diets were $0.0 ; 2.5 ; 4.5$ and $7.0 \%$, replacing respectively $0,35,65$ and $100 \%$ of crude protein (CP) from soybean meal. The diets were isoproteic $(13 \% \mathrm{CP})$ and isocaloric $(4250 \mathrm{kcal} / \mathrm{kg})$. The total fecal collection method was used for the determination of the nutrient digestibility coefficients. There was no effect of the substitution levels of soybean meal crude protein by canola meal for none of the analyzed nutrients. The average obtained values for the apparent digestibility of dry matter, gross energy, crude protein, neutral detergent fiber and acid detergent fiber were 64.04, 55.82, 62.89, 51.20 and 42.05\%, respectively. The concentrate for equines can be formulated with total substitution of soybean meal crude protein by canola meal (inclusion level of 7\%) without negatively affects the nutrient digestibilities, becoming as an alternative protein source in the diets of these animal species.
\end{abstract}

Key Words: canola meal, coefficient of digestibility, equine

\section{Introdução}

A utilização de concentrado na alimentação de eqüinos é um dos fatores que mais onera o custo de produção; desta forma, a busca de fontes alternativas para compor rações para esta espécie, no sentido de diminuir os custos de alimentação, torna-se, atualmente, fator limitante na criação de cavalos.

Nesse sentido, a canola (Brassica napus e Brassica campestris) tem se tornado importante oleaginosa em vários países de clima temperado, pois o farelo de canola, subproduto da extração do óleo, possui teor de proteína digestível semelhante ao do farelo de soja, para muitas espécies animais (BELL, 1984), constituindo-se em fonte alternativa para a alimentação animal (FAUDUET et al., 1995).
Acrescente-se que o farelo de canola possui teor de matéria seca (MS) de 93\% (BUSH et al., 1978; MUTZAR e SLINGER, 1982; SORREL e SHURSON, 1990), estando ligeiramente acima do farelo de soja, que apresenta $90 \%$. O teor de proteína bruta (PB) do farelo de canola é inferior ao do farelo de soja (respectivamente, valores de 38 e $44 \%$ ) e o teor de fibra bruta (FB) do farelo de canola, superior ao encontrado no farelo de soja (SORREL e SHURSON, 1990), de 11,1 e 6,5\%, respectivamente.

$\mathrm{O}$ alto teor de fibra bruta presente no farelo de canola deve-se à alta proporção de casca em relação ao tamanho da semente (14,0 a 16,0\%). Redução do teor de fibra pela remoção da casca é possível durante o processamento, podendo, assim, melhorar a digestibilidade da proteína e energia (SHIRES et al.,

\footnotetext{
1 Parte da Dissertação de Mestrado apresentada à UEM pelo primeiro autor.

2 Professora do Departamento de Zootecnia - UNIMAR - 17.502.000 - Marília - SP.

3 Professor do Departamento de Zootecnia - UEM - 87.020.900 - Maringá - PR. E.mail:cefurtado@uem.br
} 
1981; BELL e KEITH, 1987). Adicionalmente, nestes processos, que visam o aumento da sua viabilidade na alimentação animal, ainda há o melhoramento genético vegetal, que permite diminuição dos compostos antinutricionais (BJERGEGAARD et al., 1991; QUINSAC et al., 1994). Os níveis de glicosinolatos e ácido erúcico permitidos no farelo de canola, atualmente, são de 30 mmoles/g e $2 \%$, respectivamente, na MS livre de óleo (GRIFFITHS et al., 1998).

LEGGI et al. (1998) estudaram o efeito da substituição do farelo de soja pelo farelo de canola, nas proporções de $0,20,40$ e $60 \%$ para vacas em lactação. Os resultados de digestibilidade da ração total demonstraram que a inclusão de farelo de canola, em ração balanceada, promove queda no coeficiente de digestão, se comparado com rações que contenham apenas farelo de soja. Este fato está de acordo com os resultados obtidos por STAKE et al. (1973), WALDERN (1973) e SHARMA et al. (1980). Isto se explica provavelmente pela quantidade de casca presente no farelo de canola, o que foi confirmado por SARWAR et al. (1981), que encontraram redução na digestibilidade da proteína com a inclusão de casca.

HUSSAR e BOWLAND (1959) mostraram que a substituição de $10 \%$ do farelo de soja por farelo de canola diminuiu a digestibilidade da energia e proteína em ratos e suínos. Em outro ensaio, MANNS e BOWLAND (1963), analisando a inclusão de farelo de canola nas proporções de 0, 25, 50 e $100 \%$ da proteína suplementar, em dietas de suínos em crescimento e terminação, confirmaram o declínio da digestibilidade da energia com o aumento da concentração de farelo de canola.

Avaliando a digestibilidade dos nutrientes do farelo de canola em coelhos em crescimento, SCAPINELLO et al. (1996) encontraram os seguintes valores, com base na matéria seca total: $57,81 \%$ de MS digestível, 33,97\% de PD, $3598 \mathrm{kcal} / \mathrm{kg}$ de energia digestível (ED), 2,64\% de fibra bruta (FB) digestível, 4,56\% de fibra em detergente ácido (FDA) digestível e $14,2 \%$ de fibra de detergente neutro (FDN) digestível. O valor energético do farelo de canola, obtido pelos mesmos pesquisadores, com base na matéria natural $(2174 \mathrm{kcal} / \mathrm{kg})$, foi ligeiramente inferior ao observado por BAUDET et al. (1988), de $3350 \mathrm{kcal} / \mathrm{kg}$, para coelhos em crescimento.

Em um experimento utilizando potros desmamados, CYMBALUK (1990) avaliou três fontes protéicas: farelo de soja, farelo de canola e uma mistura de milho e cevada. A digestibilidade para fibra em detergente ácido, cálcio, fósforo e manganês não foi diferentes, significativamente, porém houve diferença na digestibilidade da PB, sendo os seus valores para farelo de soja, farelo de canola e mistura de milho e cevada, respectivamente, de 77,5; 73,7 e 68,9\%.

Apesar do potencial nutricional do farelo de canola, este ingrediente é pouco utilizado em dietas para cavalos em nosso país, principalmente em função da falta de informações científicas quanto aos aspectos nutricionais deste alimento para esta espécie animal. Portanto, o objetivo do presente trabalho foi avaliar a substituição parcial e total da proteína bruta do farelo de soja pelo farelo de canola, para cavalos, por intermédio do estudo de digestibilidade aparente, visando obter fonte protéica alternativa para a dieta de equinos, bem como diminuir o custo da alimentação.

\section{Material e Métodos}

Foram utilizados quatro eqüinos, mestiços, machos, castrados, com média de 3,5 anos e peso vivo (PV) entre 400 e $450 \mathrm{~kg}$. O delineamento experimental utilizado foi o quadrado latino $(4 \mathrm{x} 4)$ designado por COCHRAN e COX (1967). Os tratamentos consistiram de quatro dietas contendo quatro níveis diferentes $(0 ; 35 ; 65$ e $100 \%)$ de farelo de canola (FC), em substituição à proteína bruta do farelo de soja, formuladas de tal forma a serem isoprotéicas e isocalóricas, resultando na inclusão de 0,$0 ; 2,5 ; 4,5$ e 7,0\% de farelo de canola, respectivamente.

A composição química dos ingredientes, centesimal e química das dietas experimentais, encontra-se nas Tabelas 1, 2 e 3, respectivamente.

$\mathrm{O}$ experimento teve duração total de 65 dias, correspondendo, os cinco primeiros dias, à fase de adaptação (pré-experimental) dos animais às instalações e às condições de manejo.

O período experimental foi subdividido em quatro períodos de quinze dias, em que, durante cada período, os animais receberam os tratamentos designados pelo quadrado latino. A fase experimental I teve duração de dez dias, período utilizado para a adaptação dos animais aos tratamentos e a avaliação de consumo (fornecido-sobra). Durante essa fase, os animais permaneceram confinados individualmente, numa área de $25 \mathrm{~m}^{2}$ cercada com alambrado, piso de chão batido, com comedouro para fornecimento de ração e bebedouro para consumo à vontade, além de comedouro de sal para consumo ad libitum.

A quantidade de alimento fornecida aos animais foi estabelecida segundo as recomendações do 
Rev. bras. zootec.

Tabela 1 - Composição química dos ingredientes ( \% da MS $)^{1}$

Table 1 - Chemical composition of ingredients (\% DM) ${ }^{1}$

\begin{tabular}{lccccc}
\hline Alimento & $\mathrm{MS}(\%)$ & $\mathrm{PB}(\%)$ & $\mathrm{FDN}(\%)$ & $\mathrm{FDA}(\%)$ & $\mathrm{EB}(\mathrm{kcal} / \mathrm{kg})$ \\
Feed & $D M$ & $C P$ & $N D F$ & $A D F$ & GE \\
\hline Milho & 88,77 & 9,68 & 9,26 & 2,85 & 4443 \\
$\begin{array}{l}\text { Corn grain } \\
\text { Farelo de soja }\end{array}$ & 88,31 & 49,29 & 14,78 & 9,67 & 4609 \\
$\begin{array}{l}\text { Soybean meal } \\
\text { Farelo de trigo }\end{array}$ & 89,00 & 18,00 & 41,78 & 12,77 & 4615 \\
$\begin{array}{l}\text { Wheat bran } \\
\text { Farelo de canola }\end{array}$ & 89,33 & 41,42 & 27,83 & 19,42 & 4659 \\
$\begin{array}{l}\text { Canola meal } \\
\text { Feno de Rhodes }\end{array}$ & 85,43 & 7,33 & 77,96 & 42,74 & 4181 \\
$\begin{array}{l}\text { Rhodes hay } \\
\text { Thedos }\end{array}$ & & & & & \\
\hline
\end{tabular}

1 Dados obtidos no laboratório de Análise de Alimentos e Nutrição Animal/DZO/UEM.

1 Data obtained from Feed Analysis and Animal Nutrition Lab/DZO/UEM.

NATIONAL RESEARCH COUNCIL - NRC (1989), visando atender às exigências nutricionais para a categoria. Portanto, a ingestão diária de MS total foi de $2 \%$ PV, composta por $50 \%$ de concentrado e $50 \%$ de feno de rhodes (Chloris gayana Kunth.). As dietas foram fornecidas em três refeições, às $8,12 \mathrm{e}$ $17 \mathrm{~h}$, e as sobras foram retiradas e pesadas 15 minutos antes de cada refeição. Amostras do alimento foram coletadas no início de cada fase experimental.

A fase experimental II teve duração de cinco dias, os quais foram utilizados para coleta total de fezes para determinação dos seguintes coeficientes de digestibilidade aparente de: matéria seca (CDaMS), energia bruta $(\mathrm{CDaEB})$, proteína bruta $(\mathrm{CDaPB})$, fibra em detergente ácido (CDaFDA) e fibra em detergente neutro (CDaFDN), utilizando-se, para isso, as equações propostas por CHURCH (1988).

Para a coleta de fezes, os animais permaneceram confinados durante todo período em baias individuais (2,70 m de comprimento $\times 1,40 \mathrm{~m}$ de altura $\mathrm{x} 0,90 \mathrm{~m}$ de largura), piso de cimento sem cama e providos de comedouros para ração e sal e bebedouro tipo balde.

As fezes foram pesadas diariamente e homogeneizadas e alíquotas de 5\% do total diário foram coletadas. Em seguida, foram acondicionadas em sacos plásticos, devidamente identificados e armazenados em freezer, com temperatura variando de -5 e $-10^{\circ} \mathrm{C}$. Ao final de cada fase experimental II, as amostras foram descongeladas, homogeneizadas por tratamento, das quais foi retirada uma alíquota de $10 \%$ para as análises laboratoriais. As análises bromatológicas dos alimentos e fezes foram procedidas segundo metodologia da ASSOCIATION OF OFFICIAL ANALYTICAL CHEMIST AOAC, 1980).
Deve-se observar que os animais foram pesados no início e ao final de cada fase experimental, bem como vermifugados nos 30,60 e 90 dias anteriores ao início do experimento.

O modelo estatístico utilizado para a análise do coeficiente de digestibilidade dos nutrientes foi:

$$
\mathrm{Y}_{\mathrm{ijk}}=\mu+\mathrm{P}_{\mathrm{i}}+\mathrm{A}_{\mathrm{j}}+\mathrm{T}_{\mathrm{k}}+\mathrm{E}_{\mathrm{ijk}}
$$

em que $Y_{i j k}$ é valor observado dos coeficientes de digestibilidade dos nutrientes, relativo a cada indivíduo j, no período i, que recebeu ração com nível de substituição da proteína bruta do farelo de soja pelo farelo de canola $\mathrm{k} ; \mu$, constante geral; $\mathrm{P}_{\mathrm{i}}$, efeito dos

Tabela 2 - Composição centesimal das dietas experimentais (\% na MS)

Table 2 - Percentage composition of the experimental diets (\% DM)

\begin{tabular}{|c|c|c|c|c|}
\hline $\begin{array}{l}\text { Ingrediente } \\
\text { Ingredient }\end{array}$ & $\begin{array}{l}0-\mathrm{FC} \\
0-C M\end{array}$ & $\begin{array}{l}35-\mathrm{FC} \\
35-C M\end{array}$ & $\begin{array}{l}\text { 65-FC } \\
65-C M\end{array}$ & $\begin{array}{l}100-\mathrm{FC} \\
100-C M\end{array}$ \\
\hline Milho & 80,0 & 78,0 & 76,0 & 75,0 \\
\hline $\begin{array}{l}\text { Farelo de soja } \\
\text { Soybean meal }\end{array}$ & 6,0 & 4,0 & 2,0 & - \\
\hline $\begin{array}{l}\text { Farelo de trigo } \\
\text { Wheat meal }\end{array}$ & 10,0 & 11,5 & 13,5 & 14,0 \\
\hline $\begin{array}{l}\text { Farela de canola } \\
\text { Canola meal }\end{array}$ & - & 2,5 & 4,5 & 7,0 \\
\hline $\begin{array}{l}\text { Sal } \\
\text { Salt }\end{array}$ & 2,0 & 2,0 & 2,0 & 2,0 \\
\hline Premix $^{1}$ & 2,0 & 2,0 & 2,0 & 2,0 \\
\hline
\end{tabular}

${ }^{1}$ Composição do premix mineral e vitamínico (Mineral vitamin premix composition) Ca 185 g; P 180 g; Mg 25 g; Zn 5000 mg; Cu 1300 mg; Co 350 mg; Mn 2500 mg; Fe 3000 mg; I 300 mg; Se 20 mg; F 1800 mg e Vit. A 500.000 UI. 
184

Tabela 3 - Composição química das dietas experimentais (Base da MS) ${ }^{1}$

Table 3 - Chemical composition of the experimental diets (DM basis)

\begin{tabular}{lcccc}
\hline Nutrientes & $0-\mathrm{FC}$ & $35-\mathrm{FC}$ & $65-\mathrm{FC}$ & $100-\mathrm{FC}$ \\
Nutrients & $0-C M$ & $35-C M$ & $65-C M$ & $100-C M$ \\
\hline $\begin{array}{l}\text { Matéria seca (\%) } \\
\text { Dry matter }\end{array}$ & 88,34 & 88,74 & 88,80 & 87,83 \\
$\begin{array}{l}\text { Proteína bruta (\%) } \\
\text { Crude protein }\end{array}$ & 13,66 & 13,75 & 12,83 & 12,86 \\
$\begin{array}{l}\text { Lisina }(\%) \\
\text { Lysine }\end{array}$ & 0,48 & 0,48 & 0,47 & 0,46 \\
FDN $(\%)$ & 12,81 & 12,83 & 13,78 & 13,55 \\
NDF & & & & \\
FDA (\%) & 4,11 & 4,39 & 4,80 & 5,18 \\
ADF & & & & \\
EB $(\mathrm{kcal} / \mathrm{kg})$ & 4254 & 4256 & 4274 & 4222 \\
$G E$ & & & & \\
\hline
\end{tabular}

1 Dados obtidos no laboratório de Análise de Alimentos e Nutrição Animal/DZO/UEM.

2 Teor calculado segundo NRC (1989).

1 Data obtained from Feed Analysis and Animal Nutrition Lab/DZO/UEM.

2 Calculated value in accordance with NRC (1989).

períodos, sendo $\mathrm{i}=1,2,3$ e $4 ; \mathrm{A}_{\mathrm{j}}$, efeito dos animais, sendo $\mathrm{j}=1,2,3 \mathrm{e} 4 ; \mathrm{T}_{\mathrm{k}}$, efeito do nível de substituição da proteína bruta do farelo de soja pelo farelo de canola, sendo $\mathrm{k}=1,2,3$ e $4 ; \mathrm{E}_{\mathrm{ijk}}$, erro aleatório associado a cada observação.

A análise estatística das variáveis estudadas, relativas à digestibilidade dos nutrientes, foi efetuada considerando-se a técnica da análise da variância para delineamentos em quadrado latino (quatro períodos x quatro animais), com desdobramento dos graus de liberdade de tratamentos (níveis de canola no concentrado), em polinômios ortogonais
(COCHRAN e COX, 1967). Nesta análise de regressão dos coeficientes de digestibilidade dos nutrientes, em função dos níveis de farelo de canola, não foi considerado o nível zero de canola.

A análises estatísticas foram realizadas, utilizando-se o programa Statystical Analisys System (SAS, 1986) e as conclusões foram obtidas considerando-se $5 \%$ como nível de significância.

\section{Resultados e Discussão}

Os resultados dos coeficientes de digestibilidade aparente (CDa) da MS, EB, PB, FDN e FDA dos eqüinos encontram-se na Tabela 4 . A análise permitiu verificar que não foram detectadas diferenças $(P>0,05)$ entre os tratamentos.

O coeficiente de digestibilidade aparente da PB, do presente trabalho, não diferiu, significativamente, entre as dietas, apresentando valor médio de $62,89 \%$, que foi inferior ao valor médio de $75,6 \%$, encontrado por CYMBALUK (1990), trabalhando com potros de 6 a 12 meses. Por outro lado, o mesmo autor observou, ainda, diferenças significativas entre as fontes protéicas (canola e soja) para o CDPB, na qual os valores encontrados foram 73,7 e $77,5 \%$, respectivamente, diferentemente do que foi observado no presente estudo. Considerando o CDaFDA, CYMBALUK (1990) encontrou valor de 35,55\%, o qual não foi significativamente diferente entre dietas contendo farelos de soja ou de canola, sendo, portanto, concordante com a presente pesquisa, porém inferior ao valor médio obtido neste estudo.

As diferenças observadas entre os resultados de CYMBALUK (1990), quando comparadas ao pre-

Tabela 4 - Coeficientes de digestibilidade aparente da matéria seca e nutrientes (\% na MS) em eqüinos alimentados com dietas contendo diferentes níveis (\%) de substituição por farelo de canola (FC)

Table 4 - Coefficients of apparent digestibility of dry matter and nutrients (\% DM) in equines fed diets with different canola meal (CM)replacement levels (\%)

\begin{tabular}{|c|c|c|c|c|c|c|}
\hline $\begin{array}{l}\text { Variável } \\
\text { Variable }\end{array}$ & $\begin{array}{l}0-\mathrm{FC} \\
0-C M\end{array}$ & $\begin{array}{l}35-\mathrm{FC} \\
35-C M\end{array}$ & $\begin{array}{l}65-\mathrm{FC} \\
65-C M\end{array}$ & $\begin{array}{l}100-\mathrm{FC} \\
100-C M\end{array}$ & $\begin{array}{l}\mathrm{p} \text {-value } \\
p \text {-value }\end{array}$ & $\begin{array}{c}\mathrm{CV}(\%)^{1} \\
C V(\%)\end{array}$ \\
\hline $\begin{array}{l}\text { CdaMS } \\
A D C D M\end{array}$ & 64,55 & 66,44 & 61,40 & 63,75 & 0,23 & 4,76 \\
\hline $\begin{array}{l}\text { CdaEB } \\
A D C G E\end{array}$ & 53,13 & 58,15 & 54,45 & 57,54 & 0,40 & 8,05 \\
\hline $\begin{array}{l}\text { CdaPB } \\
A D C C P\end{array}$ & 62,88 & 65,39 & 60,02 & 63,27 & 0,34 & 6,04 \\
\hline $\begin{array}{l}\text { CdaFDN } \\
A D C N D F\end{array}$ & 50,94 & 52,71 & 48,70 & 52,46 & 0,78 & 11,88 \\
\hline $\begin{array}{l}\text { CdaFDA } \\
\text { AdcaDF }\end{array}$ & 42,81 & 44,65 & 38,80 & 41,94 & 0,63 & 14,92 \\
\hline
\end{tabular}

\footnotetext{
${ }^{1} \mathrm{CV}=$ coeficiente de variação ( $\mathrm{CV}=$ Coefficient of variation).
}

$\mathrm{P}>0,05$. 
sente experimento, indicam que os CDa da PB e FDA possuem comportamentos distintos em relação à idade dos eqüinos, sugerindo que potros são mais eficientes em digerir a proteína da dieta do que eqüinos adultos, porém ainda não possuem nesta fase microflora cecal totalmente capacitada para digerir de forma adequada os constituintes da parede celular dos alimentos.

Os dados dos CDa dos nutrientes do presente trabalho foram similares aos resultados encontrados por ARAÚJO (1992), exceto para o CDaEB, o qual obteve valores para CDa da MS, EB, PB, FDN e FDA, respectivamente, de 63,75; 63,93; 64,59; 51,52 e $41,15 \%$. Vale ressaltar que os valores observados pelo autor supracitado foram obtidos em equiinos alimentados com ração à base de milho, farelos de trigo e de soja, contendo $12,73 \%$ de PB.

Trabalhos conduzidos por PEREIRA et al. (1989), SAINT JUST (1989), ALVARENGA et al. (1997), WHITAKER e CARVALHO (1997) e ALMEIDA et al. (1998), utilizando eqüinos alimentados com rações à base de feno, milho, farelo de soja e/ou sorgo com níveis protéicos de 12 a 18,5\% de PB, relataram valores de CDa da MS e PB variando de 52,8 a $68,6 \%$, e de 60,83 a $77,05 \%$, respectivamente. Estes valores foram próximos aos CDa da MS e PB obtidos no presente trabalho para todos os níveis de substituição de farelo de canola. Por outro lado, os CDa da FDA obtidos com a utilização do farelo de canola foram superiores ao relatado por WHITAKER e CARVALHO (1997), os quais obtiveram valor de $36,8 \%$ para o CDa da FDA em rações substituindo o milho pelo sorgo.

\section{Conclusões}

A substituição total do farelo de soja pelo farelo de canola não afetou negativamente a palatabilidade e o consumo das dietas experimentais.

Os concentrados para eqüinos podem ser formulados com substituição total da proteína bruta do farelo de soja pelo farelo de canola (nível de inclusão de $7 \%$ ), sem afetar adversamente a digestibilidade dos nutrientes, tornando-se, assim, uma fonte protéica alternativa para as dietas desta espécie animal.

\section{Referências Bibliográficas}

ALMEIDA, F.Q., VALADARES FILHO, S.C., QUEIROZ, A.C. et al. 1998. Digestibilidade aparente e verdadeira précecal e total da proteína em dietas com diferentes níveis protéicos em eqüinos. R. Bras. Zootec., 27(3):521-529.

ALVARENGA, R.S., LEÃO, M.I., VALADARES FILHO, S.C. et al. 1997. Digestibilidade aparente total e parcial em eqüinos íleo-fistulados. R. Bras. Zootec., 26(4):736-743.

ARAÚJO, L.O.D. Comparação da digestibilidade aparente em equídeos, submetidos a dieta composta de concentrado $e$ volumoso, fornecidos com diferentes intervalos de tempo. Belo Horizonte, MG: UFMG, 1992. 72p. Dissertação (Mestrado em Zootecnia) - Universidade Federal de Minas Gerais, 1992.

ASSOCIATION OF OFFICIAL ANALYTICAL CHEMIST AOAC. 1980. Official methods of the analysis. 13.ed. Washington, DC. 1018p.

BAUDET, J.J., BURGHART, P., EVRARD, J. 1988 Cahierdetechnique colza - Tourteau et basse tineur en glucosinolatis (BTG). CETION: Paris. 52p.

BELL, J.M. 1984. Nutrients and toxicants in rapeseed meal. A review. J. Anim. Sci., 58(4):996-1010.

BELL, J.M., KEITH, M.O. 1987. Feeding value for pis of canola meal derived from westar and triazine - tolerant cultivars. Can. J. Anim. Sci., 67:811-819.

BJERGEGAARD, C., JENSEN, S.K., SOERENSEN, H. Diectary fibres in oilseed rape: properties and effects on the digestibility of rapeseed meal. In: GCIRC, 1991, Saskatoon. Proceedings.. SASKATOON, Canada, 1991. p.448-443.

BUSH, R.J., NICHOLSON, J.W.G., McINTRYE, T.M. et al. 1978. Comparacion of Candle and Tower rapeseed meals in lamb, sheep and beef steers rations. Can J. Anim. Sci., 58(23):369-376.

CHURCH, D.C. 1988. The ruminat animal. Digestive physiology and nutrition. Englewood Cliffs: Prentice Hall. 564p.

COCHRAN, W.G., COX, G.M. 1967. Experimental designs. New York: John Wiley and Sons. p.617.

CYMBALUK, N.F. 1990. Using canola meal in growing draft horse diet. Eq. Pract., 12(4):13-19.

FAUDUET, H., COIC, J.P., LESSIRE, M. et al. 1995. Rapeseed meal upgrading - pilot scale preparation of rapeseed meal materials with high or low glucosinolate contents. Anim. Feed Sci. Technol., 56:99-109.

GRIFFITHS, D.W., BIRCH, A.N.E., HILLMAN, J.R. 1998. Antinutritional compounds in the Brassicaceae: Analysis, biosynthesis, chemistry and dietary effects. J. Hort. Sci. Biotechnol., 73(1):1-18.

HUSSAR, N., BOWLAND, J.P. 1959. Rapeseed oil meal as a protein supplement for swine and rats. II Energy and nitrogen digestibility and nitrogen retention. Can J. Anim. Sci., 39:94

LEGGI, TC.S.S., SANTOS,G.T., FURLAN,A.C. et al. 1998. Utilização do farelo de canola (Brassica napus) na alimentação de vacas leiteras. R. Bras. Zootec., 27(4):770-776.

MANNS, J.G., BOWLAND, J.P. 1963. Solvent-extracted rapeseed oil meal as a protein source for pigs and rats. II Nitrogen digestibility and retention; and energy and dry matter digestibility. Can J. Anim. Sci., 43:264.

MUZTAR, J.A., SLINGER, S.J. 1982. The true metabolizable energy and amino acid content of candle and regent canola meals. Can. J. Anim. Sci., 62(2):521-525.

NATIONAL RESEARCH COUNCIL - NRC. Nutrient Requeriments of Horses. 5 revised ed. Washington: National Academy Press., 1989. 100p.

PEREIRA, J.C., CARMO, M.B., MOTTA, V.C.F. et al. 1989 Feno de aveia associado ao concentrado em diferentes proporções na alimentação de eqüinos. R. Soc. Bras. Zoot., 18(5):359-366.

QUINSAC, A., LESSIRE, M., KROUTI, M. et al. 1994 Improvement in the nutritive value of high or low glucosinolate rapeseed meal by aqueous extration. Anim. Feed Sci. Technol., 48:265-272.

SAINT JUST, C.A. Digestibilidade de nutrientes de rações 
contendo milho e sorgo em éguas gestantes. Piracicaba, ESALQ-USP, 1989. 56p. Dissertação (Mestrado em Agronomia). Escola Superior de Agricultura Luiz de Queiroz Universidade de São Paulo, 1989.

SARWAR, G., BELL, J.M., SHARBY, T.F. et al. 1981. Nutritional evaluation of meals and meal fractions derived from rape and mustard seed. Can J. Anim. Sci., 61:719.

SCAPINELLO, C., FURLAN, A.C., MOREIRA, I. et al. 1996. Valor nutritivo do farelo de canola e da semente de canola para coelhos em crescimento. R. Bras. Zootec, 25(6):1115-1123.

SHARMA, H.R., INGALLS, J.R., DEVLINI, T.J. 1980. Apparent digestibility of tower and candle rapeseed meals by Holstein and bull calves. Can J. Anim. Sci., 60(4):915-918.

SHIRES, A., BELL, J.M., BLAIR, R. 1981. Nutritional value of unextracted and extracted dehulled canola rapeseed for chicken. Can J. Anim. Sci., 61(4):989-998.

SORREL, E.R., SHURSON, G.C. 1990. Use of canola meal in swine diets reviewed. Feedstuffs, 62:13-16.
STAKE, P.E., OWENS, M.J., SCHINGOETHE, D.J. 1973. Rapeseed, sunflower and soybean meal supplementation of calf rations. J. Dairy Sci., 56:783-788.

STATISTICAL ANALYSIS SYSTEM. SAS system for linear models. Cary: SAS Institute, 1986. 211p.

WALDERN, D.E. 1973. Rapeseed meal versus soybean meal as the only protein supplement for lactating cows fed corn silage roughage rations. Can J. Anim. Sci., 53:107-120.

WHITAKER, H. M.A., CARVALHO, R.L. 1997. Substituição do milho pelo sorgo em rações para eqüinos. R. Bras. Zootec., 26(1):139-143.

Recebido em: 06/09/99

Aceito em: 21/09/00 